\title{
Sleep in Humans Stabilizes Pattern Separation Performance
}

\author{
Annika Hanert, ${ }^{1}$ @Frederik D. Weber, ${ }^{2}$ Anya Pedersen, ${ }^{3}$ Jan Born, ${ }^{2}$ and ${ }^{-T h o r s t e n ~ B a r t s c h ~}{ }^{1}$ \\ ${ }^{1}$ Department of Neurology, Memory Disorders and Plasticity Group, University Hospital Schleswig-Holstein, Kiel, University of Kiel, 24105 Kiel, Germany, \\ ${ }^{2}$ Institute for Medical Psychology and Behavioral Neurobiology, University of Tübingen, 72074 Tübingen, Germany, and ${ }^{3}$ Department of Psychology, \\ Clinical Psychology and Psychotherapy, University of Kiel, 24118 Kiel, Germany
}

Replay of hippocampal neural representations during sleep is thought to promote systems consolidation of declarative memory. How this reprocessing of memory during sleep affects the hippocampal representation itself, is unclear. Here we tested hippocampal stimulus processing (i.e., pattern separation) before and after periods of sleep and wakefulness in humans (female and male participants). Pattern separation deteriorated across the wake period but remained stable across sleep $(p=0.013)$ with this sleep-wake difference being most pronounced for stimuli with low similarity to targets $(p=0.006)$. Stimuli with the highest similarity showed a reversed pattern with reduced pattern separation performance after sleep $(p=0.038)$. Pattern separation performance was positively correlated with sleep spindle density, slow oscillation density, and theta power phase-locked to slow oscillations. Sleep, presumably by neural memory replay, shapes hippocampal representations and enhances computations of pattern separation to subsequent presentation of similar stimuli.

Key words: consolidation; hippocampus; memory; pattern separation; sleep

\section{Significance Statement}

The consolidation of hippocampus-dependent memories is causally related to reactivation during sleep of previously encoded representations. Here, we show that reactivation-based consolidation processes during sleep shape the hippocampal representation itself. We studied the effect of sleep and wakefulness on pattern separation (i.e., orthogonalization of similar representations) and completion performance (i.e., recall of a memory in light of noisy input) that are essential cognitive elements of encoding and retrieval of information by the hippocampus. Our results demonstrate that pattern separation was stabilized after sleep but diminished after wakefulness. We further showed that pattern separation was related to EEG oscillatory parameters of non-REM sleep serving as markers of sleep-dependent memory consolidation and hippocampal reactivation.

\section{Introduction}

Whereas the wake state is optimal for the encoding of information, sleep following encoding is considered a brain state favoring the formation of long-term memory (Rasch and Born, 2013). In particular, sleep appears to benefit hippocampus-dependent (i.e., declarative) memory for episodes and facts (Inostroza and Born, 2013). The consolidation of hippocampus-dependent memories during sleep is causally related to the replay of patterns of neural activity that were present during encoding of the information during prior wakefulness (Girardeau et al., 2009; Ego-Stengel and Wilson, 2010). In rats, firing patterns of hippocampal place cell

Received April 29, 2017; revised Sept. 20, 2017; accepted Sept. 27, 2017.

Author contributions: A.H., A.P., J.B., and T.B. designed research; A.H. and T.B. performed research; A.H., F.D.W., A.P., and T.B. analyzed data; A.H., F.D.W., A.P., J.B., and T.B. wrote the paper.

The present study was supported by Deutsche Forschungsgemeinschaft (SFB 654, A14, "Plasticity and Sleep," and FOR 2093) and the Medical Faculty of the University of Kiel.

The authors declare no competing financial interests.

Correspondence should be addressed to Dr. Thorsten Bartsch, Memory Disorders and Plasticity Group, Department of Neurology, University Hospital Schleswig-Holstein, Kiel, Arnold Heller Strasse 3, 24105 Kiel, Germany. E-mail: t.bartsch@neurologie.uni-kiel.de.

DOI:10.1523/JNEUROSCI.1189-17.2017

Copyright $\odot 2017$ the authors $\quad 0270-6474 / 17 / 3712238-09 \$ 15.00 / 0$ assemblies evoked during navigating through a maze are replayed during subsequent slow-wave sleep (SWS; Wilson and McNaughton, 1994; O’Neill et al., 2010). Such replay activity can be experimentally induced by presenting cues that were present during prior learning, and again during SWS after learning (Rasch et al., 2007; Bendor and Wilson, 2012), which indeed enhanced the memory encoded before sleep, thus proving the causal role of neural reactivations for the consolidation of hippocampusdependent memory during sleep. The reactivated memory information is thought to be transmitted to extrahippocampal, mainly neocortical networks serving as long-term store (Diekelmann and Born, 2010). This process is supported by the phase locking of the three prime rhythms of the EEG during SWS accompanying hippocampal replay (i.e., hippocampal ripples that nest into thalamic $12-15 \mathrm{~Hz}$ spindle oscillations, which themselves nest into the up-states of the neocortical $<1 \mathrm{~Hz}$ slow oscillations; Sirota et al., 2003; Clemens et al., 2007; Staresina et al., 2015).

Hippocampal memory reactivations, however, aside from promoting extrahippocampal changes, are expected to also change the features of the hippocampal representation per se, possibly resembling the effects of re-encoding (Karpicke and Roediger, 2008; 
Inostroza and Born, 2013). Pattern separation (PatSep) and pattern completion (PatComp) represent two principal features of hippocampal memory processing (McNaughton and Morris, 1987; O'Reilly and McClelland, 1994). Pattern separation refers to the capability of the hippocampus to form nonoverlapping orthogonal neural representations from similar sequential episodic stimulus inputs (McClelland et al., 1995). Pattern completion refers to the recall of a memory based on the presentation of incomplete, noisy, or degraded stimulus patterns (Norman and O'Reilly, 2003). Based on the hippocampal circuit structure with its recurrent associative networks embedded into the unidirectional trisynaptic pathway, both processes have been linked to computations in different hippocampal subnetworks (O'Reilly and McClelland, 1994; Bartsch et al., 2010; Bartsch et al., 2011). Indeed, it has been shown that the hippocampal dentate gyrus (DG) is essential for pattern separation and that CA3 networks are involved in pattern completion (Guzowski et al., 2004; Leutgeb et al., 2007; Neunuebel and Knierim, 2014). In humans, high-resolution imaging studies confirmed the role of the DG and CA 3 in pattern separation and determined that the CA1 area contributed to pattern completion, using mnemonic similarity recognition tasks (Bakker et al., 2008; Yassa et al., 2010, 2011a; Lacy et al., 2011; Berron et al., 2016).

Here, we used the mnemonic similarity task (MST) to study how memory processing during sleep affects representations toward enhancing and/or diminishing pattern separation. We recorded sleep to identify EEG oscillations known to synchronize hippocampal memory replay activity (i.e., spindles) originating from thalamic networks and the neocortical slow oscillations.

\section{Materials and Methods}

\section{Participants}

Thirteen healthy students (mean age, $23.46 \pm 0.5$ years; age range, $21-26$ years; 10 women) participated in the study. Participants were recruited via advertisement at the university and received monetary compensation $(€ 75)$ after completion. Participants were free of neurological or psychiatric disorders and did not use any medication. They kept a regular sleep/wake cycle and did not engage in any stressful activities (e.g., exams, night shift) for an interval of at least 6 weeks before the experiments. General sleep quality was assessed via the Pittsburgh Sleep Quality Index (Buysse et al., 1989). None of the subjects had previously participated in an experiment in our laboratory. Participants had to refrain from drinking alcohol and caffeine, from stressful physical activities, and from napping on the experimental days. They were all vigilant and alert according to the subject's report at all time points tests were performed. Every participant gave written informed consent before the study, which was approved by the local ethics committee.

\section{Mnemonic similarity task}

The MST is an established recognition memory task that has been shown to tax pattern separation (Kirwan and Stark, 2007; Bakker et al., 2008; Toner et al., 2009; Yassa et al., 2010, 2011b; Ally et al., 2013; Stark et al., 2013; Bennett and Stark, 2016; http://faculty.sites.uci.edu/starklab/ mnemonic-similarity-task-mst/). The MST comprises an encoding and a recall phase. For the encoding phase, the participant is asked to classify 256 items (i.e., everyday objects) as either an indoor or an outdoor object via button press on a keyboard. Objects are sequentially presented on a computer monitor each for $2 \mathrm{~s}$ with a $0.5 \mathrm{~s}$ interstimulus interval. The two recall phases of the experiment (immediate and delayed) comprised 192 items (128 old plus 64 new items) each including (1) 64 exact repetitions of the previously seen objects ("targets"), (2) 64 objects that were similar to the previously seen objects ("lures"), and (3) 64 new objects that the participant had not seen before ("foils"). Half of the stimulus set used at encoding (128 items) was used for immediate recall testing, the other half for delayed recall testing. For testing recall, participants indicated (within the $2 \mathrm{~s}$ of item presentation) whether a presented object was "old", "sim- ilar," or "new" by button press. In this context, the answers to lure items were of substantial significance, implying a successful pattern separation when correctly responding "similar" (Toner et al., 2009; Yassa et al., 2010). The order of sets across Wake and Sleep as well as for immediate and delayed recall was randomized, and the stimuli within each set followed a pseudorandomized order. Responses at recall enabled calculation of two different scores that comprise performance measures of pattern separation and recognition memory:

Pattern separation score. Behavioral pattern separation was determined by the correct discrimination of a lure item from its target counterpart as follows: PatSep score $=[p$ (correct similar response to lures $)-p$ (false similar response to foils)]. The score was thus corrected for a possible response bias toward exhibiting a tendency to use the similar response (Yassa et al., 2010, 2011b; Stark et al., 2013; Bennett and Stark, 2016).

To assess the performance of pattern separation as a function of lure similarity, PatSep scores were calculated for the five degrees of lure similarity to a target object (1-5: most similar to least similar; Yassa et al., 2010; Lacy et al., 2011). The similarity bins were the same as in previous studies (Stark et al., 2013; Bennett and Stark, 2016).

Recognition memory score. Recognition memory was assessed by the number of correct responses to targets. To correct for response bias to preferentially respond with the target button, the number of incorrect target responses to foils was subtracted: recognition memory (RM) score $=[p$ (correct old response to targets) $-p$ (false old response to foils)] (Stark et al., 2013).

\section{Experimental design and procedure}

Each participant attended both the Wake and Sleep conditions, following a within-subject crossover design. Participants were randomly assigned to one of the conditions to perform at first. The second condition took place $42.54 \pm 5.33 \mathrm{~d}$ later. Each condition started with encoding of the MST items (encoding phase) followed by an immediate recall test, followed by a $9 \mathrm{~h}$ retention interval covering either nocturnal sleep (Sleep condition) or daytime wakefulness (Wake condition). Thereafter, recall was tested again (delayed recall, Fig. 1). Encoding and immediate recall testing lasted $\sim 30 \mathrm{~min}$, and the delayed recall an additional $15 \mathrm{~min}$.

For the Sleep condition, subjects spent one adaptation night before the test night in the laboratory to habituate to sleeping under laboratory conditions including polysomnographic recordings. On experimental days, encoding and immediate recall took place in the evening from 9:00 to 10:00 P.M. Then, subjects were prepared for polysomnographic recordings, and lights were turned off at 11:00 P.M. Subjects were awakened at 07:00 A.M., and recall testing started at $\sim 7: 30$ A.M.

After delayed recall testing in the Sleep condition, participants completed a neuropsychological test battery evaluating (1) short-term memory by the Rey Auditory Verbal Learning Test (Rey, 1941), (2) executive function by the Trail Making Test A and B (Reitan, 1979), (3) verbal fluency by the Regensburg Word Fluency Test (Aschenbrenner et al., 2000), (4) working memory by the digit span test (Wechsler, 1997), and (5) general intelligence by the Multiple Choice Vocabulary Intelligence Test (German equivalent of the National Adult Reading Test by Nelson [1982]; Lehrl, 2005). Also, handedness was assessed via the Edinburgh Handedness Inventory (Oldfield, 1971).

In the Wake condition, encoding and immediate recall testing took place in the morning between 8:00 and 9:00 A.M., and delayed recall was tested between 6:00 and 7:00 P.M. Participants were told to sleep at least $6 \mathrm{~h}$, but at most $8 \mathrm{~h}$, the night before testing. During the wake interval, participants were not engaged in stressful physical and emotional activities and demanding cognitive tasks like exam preparations.

\section{Polysomnography, EEG power spectra, slow oscillations, and sleep spindles}

Polysomnography included recordings of electroencephalogram (EEG) from F3, F4, C3, C4, O1, and O2 (international 10-20 system, referenced to electrodes at the mastoids, ground at $\mathrm{AFz}$ ), electrooculogram (EOG) from electrodes around the eyes, and electrocardiogram (ECG). Signals were recorded using the SOMNOscreen EEG 10-20 system (Somnomedics) digitized at 128 or $256 \mathrm{~Hz}$ and filtered (EEG, 0.2-35 Hz; EOG, 0.2-10 $\mathrm{Hz}$; ECG lowpass, $50 \mathrm{~Hz}$ ). Sleep stages were scored off-line according to 


\section{Encoding 256 items + Immediate recall 192 items Indoor or outdoor? Old, similar or new?}

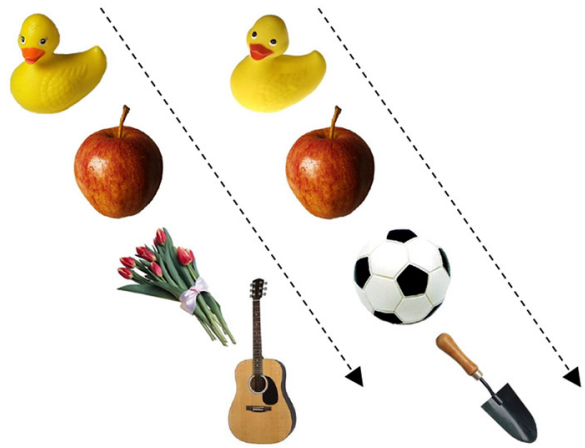

Delayed recall 192 items

Old, similar or new?

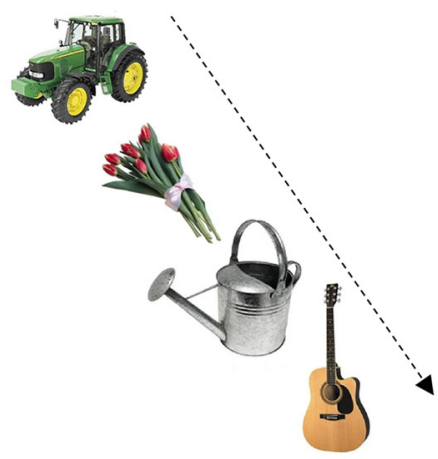

$2.0 \mathrm{sec}+0.5 \mathrm{sec}$ ISI

Retention Time

\begin{tabular}{|l|l|l|l|}
\hline Sleep condition & $9-10 \mathrm{pm}$ & Sleep & $7-8 \mathrm{am}$ \\
\hline
\end{tabular}

\begin{tabular}{|l|l|l|l}
\hline Wake condition & $8-9$ am \\
\hline
\end{tabular}

Wake

$6-7 \mathrm{pm}$

Figure 1. Design and procedures. Each participant performed on a Sleep and a Wake condition separated by at least 3 weeks. Conditions started with encoding of 256 MST items followed by an immediate recognition test (192 items), followed by a $9 \mathrm{~h}$ retention interval covering nocturnal sleep (Sleep condition) or daytime wakefulness (Wake condition). Thereafter, delayed recall (192 items not used for immediate recall) was tested. Displayed pictures in the graph are taken from the original image database of the MST. ISI, Interstimulus interval.

American Academy of Sleep Medicine criteria by a trained rater. For each subject, total sleep time, time spent in sleep stage 1 (S1), stage 2 (S2), SWS (i.e., stages 3 and 4), and rapid eye movement (REM) sleep and movement artifacts were detected. Sleep onset was defined with reference to lights off by the first occurrence of stage 1 sleep followed by stage 2 sleep. Analyses were based on the central channels.

More fine-grained EEG analyses were performed to track the association of pattern separation and completion with specific sleep EEG oscillatory parameters during non-REM sleep (S2 and SWS; i.e., specifically with EEG power in different frequency band, slow oscillations, and sleep spindles). Analysis was based on epochs free of visually identified EEG artifacts and performed using the SpiSOP toolbox (http://www.spisop. org) based on MATLAB 2015a (MathWorks) and FieldTrip (Oostenveld et al., 2011). Additionally, EEG activity occurring phase-locked to the slow oscillations was explored. Before the analyses, EEG signals were downsampled to $128 \mathrm{~Hz}$. The algorithms are briefly described in the following sections.

Power spectral analyses. Power spectra were calculated on consecutive $5 \mathrm{~s}$ intervals of non-REM sleep, which overlapped in time by $4 \mathrm{~s}$. Intervals were tapered by a single Hanning window before applying fast Fourier transformation that resulted in interval power spectra with a frequency resolution of $0.2 \mathrm{~Hz}$. Power spectra were then averaged across all blocks (Welch's method) and normalized by the effective noise bandwidth to obtain power spectral density estimates for all data. Mean power density in the following frequency bands was determined for each EEG channel separately, as follows: slow oscillation $(0.5-1 \mathrm{~Hz})$; delta $(1-4 \mathrm{~Hz})$; slowwave activity $(0.5-4 \mathrm{~Hz})$; theta $(4-8 \mathrm{~Hz})$; slow spindles $(9-12 \mathrm{~Hz})$; and fast spindles $(12-15 \mathrm{~Hz})$.

Slow oscillation detection. Identification of slow oscillations was performed in non-REM sleep, separately for S2 and SWS. Detection was based on a previously published algorithm (Mölle et al., 2002). For each EEG channel, the signal was filtered between 0.5 and $3.5 \mathrm{~Hz}(-3 \mathrm{~dB}$ rolloff) using a digital finite impulse response filter (Butterworth filter, order of 4). Then, all time intervals with consecutive positive-to-negative zero crossings were marked as putative slow oscillation if their durations corresponded to a frequency between 0.5 and $1.11 \mathrm{~Hz}$ (Ngo et al., 2013). Putative slow oscillations with lower amplitudes were immediately excluded when both negative and positive half-wave amplitudes were smaller than -15 and $+10 \mu \mathrm{V}$, respectively. A slow oscillation was then identified if its negative half-wave peak potential was $>1.25$ times the mean of the negative half-wave peak of all putatively detected slow oscil- lations in the respective EEG channel, and also only if the amplitude of the positive half-wave peak was $>1.25$ times the mean positive half-wave amplitude of all other putatively detected slow oscillations within this channel. For each individual and channel, the number of slow oscillations, their density (per minutes of non-REM sleep), mean amplitude, and slope (ratio between negative half-wave peak amplitude and the time between the negative peak to the next zero crossing; Riedner et al., 2007) were calculated.

Spindle detection. Spindle identification focused on conventional (fast) spindles in central channels $(\mathrm{C} 3, \mathrm{C} 4)$ as they typically occur in centroparietal brain regions (De Gennaro and Ferrara, 2003; Mölle et al., 2011). Spindle frequency peaks were visually identified from non-REM power spectra according to their expected power maximum in the $12-15 \mathrm{~Hz}$ band (mean peak, $13.82 \pm 0.11 \mathrm{~Hz}$ ). For each EEG channel, the nonREM epochs signal was filtered with a bandpass of $\pm 1 \mathrm{~Hz}$ ( $-3 \mathrm{~dB}$ cutoff, two filter passings) around the individual spindle frequency peaks. Then, using a sliding window with a size of $0.2 \mathrm{~s}$ the root mean square (RMS) was computed, and the resulting signal was smoothed in the same window with a moving average. A spindle was detected when the smoothed RMS signal exceeded an individual amplitude threshold 1.5 times the SD of the filtered signal for $0.5-3 \mathrm{~s}$. The threshold crossings marked the beginning and the end of the spindle event. Spindles were excluded with amplitudes $>200 \mu \mathrm{V}$. For each subject and channel, absolute spindle counts, spindle density (per 30 s non-REM epochs), mean amplitude, and mean length were calculated. For spindle analyses, data from one outlier (with a spindle density $>2$ SDs from the mean) were removed (resulting $n=12$ ).

EEG activity phase-locked to slow oscillations. Time-frequency power was calculated separately for each detected slow oscillation in frequency steps of $0.2 \mathrm{~Hz}$ and a range of $2-24 \mathrm{~Hz}$ using continuous Morlet wavelets with a length of 7 cycles that were applied to the EEG every $0.02 \mathrm{~s}$, time locked to the negative slow oscillation peak. Time-frequency data were then averaged for each subject. Averaged time-frequency power values were $\log$ transformed (in decibels) and, then, normalized by dividing them by the average power in a $\pm 2 \mathrm{~s}$ window around the negative slow oscillation peak for each respective frequency bin. For statistical comparisons, for each subject the phase-locked power in two frequency bands of interest (Ngo et al., 2013; Schreiner and Rasch, 2015) was averaged across specific time windows (i.e., theta activity; $4-8 \mathrm{~Hz}$ ) occurring at the slow oscillation down state $(-0.5$ to $+0.25 \mathrm{~s}$ around the negative slow oscillation peak) and spindle activity $(12-16 \mathrm{~Hz})$ occurring at the subsequent 
slow oscillation up state $(+0.25-1 \mathrm{~s}$ with reference to the negative slow oscillation peak).

\section{Statistical analyses}

To analyze differences between the Sleep and Wake conditions for MST parameters, difference values (delayed minus immediate recall scores) were calculated. A Shapiro-Wilk test for normality was applied to all parameters before statistical testing. Paired-samples $t$ tests were used for the analysis of differences between Sleep and Wake conditions regarding PatSep, and RM scores. Also, one-sample $t$ tests against zero were conducted to show a stabilization, decrease, or increase of the difference values of PatSep and RM scores. A two-factorial repeated-measures ANOVA was performed for examining sleep/wake differences regarding the different degrees of lure similarity with Sleep/Wake and lure similarity as within-subject factors. If the sphericity assumption was violated, degrees of freedom were reported according to a Greenhouse-Geisser correction. Post hoc paired-samples $t$ tests (Fisher's least significant difference method) were performed to identify differences between the Sleep and Wake condition. For a further analysis to depict the relation between the PatSep score and lure similarity, Spearman's $\rho$ values for immediate and delayed recall were separately calculated for every subject. One-sample Wilcoxon signed rank tests against zero were used to demonstrate graded decreases or increases of scores in relation to lure similarity. To examine differences between the correlational coefficients, Wilcoxon signed rank tests were calculated. To analyze the relationship between PatSep scores and sleep EEG parameters, Pearson productmoment correlations were computed for normal distributed and linearly related variables, for other variables Spearman's $\rho$ was used. Considering the exploratory nature of the correlational analysis, correction for multiple comparisons was excluded. All statistical analyses were performed using two-tailed tests. The significance level was set to $p<0.05$. Data are expressed as the mean \pm SEM.

\section{Results}

Each of 13 healthy students was tested during a Sleep and a Wake condition (Fig. 1, experimental design and procedure). On both conditions, the encoding of MST items (color photographs of everyday objects) was followed by an immediate recall and a $9 \mathrm{~h}$ retention interval covering either nocturnal sleep or daytime wakefulness. Thereafter, delayed recall of MST items was tested. At recall, subjects were required to judge presented objects as "old target," "similar lure," or "new foil" items, enabling the calculation of individual scores of PatSep performance and recognition memory. The assessment of the effects of sleep was based on individual retention scores (i.e., delayed minus immediate recall).

\section{Pattern separation and recognition memory}

PatSep scores were distinctly higher after sleep than after wakefulness $\left(t_{(12)}=-3.08, p=0.010\right.$; Fig. 2$)$. Additionally, the delayed-immediate recall difference revealed that PatSep scores remained stable across sleep (mean score, $-3.32 \pm 2.98 ; t_{(12)}=$ $-1.16, p=0.287$, for test against 0 ), whereas scores strongly decreased across wakefulness (mean score, $-20.82 \pm 4.24 ; t_{(12)}=$ $-4.91, p=0.00004)$. Regarding recognition memory, the scores were higher after sleep (mean score, $-7.54 \pm 2.71$ ) than wakefulness (mean score, $-23.77 \pm 3.12 ; t_{(12)}=-3.603, p=0.004$; Fig. 2, Table 1).

We examined whether the effects of sleep on the PatSep score depended on the degree of the lure similarity (ranging from 1 to 5 , from most similar to least similar to target). The stabilization of PatSep scores after sleep, compared with the decrease across wakefulness, was most pronounced for the least similar (5) lures $\left(F_{(4,48)}=8.28, p=0.00004\right.$, Sleep/Wake $\times$ similarity interaction, in a $2 \times 5$ repeated-measures ANOVA; Fig. $3 a$ ). The effect of sleep decreased with increasing lure similarity and, notably, was

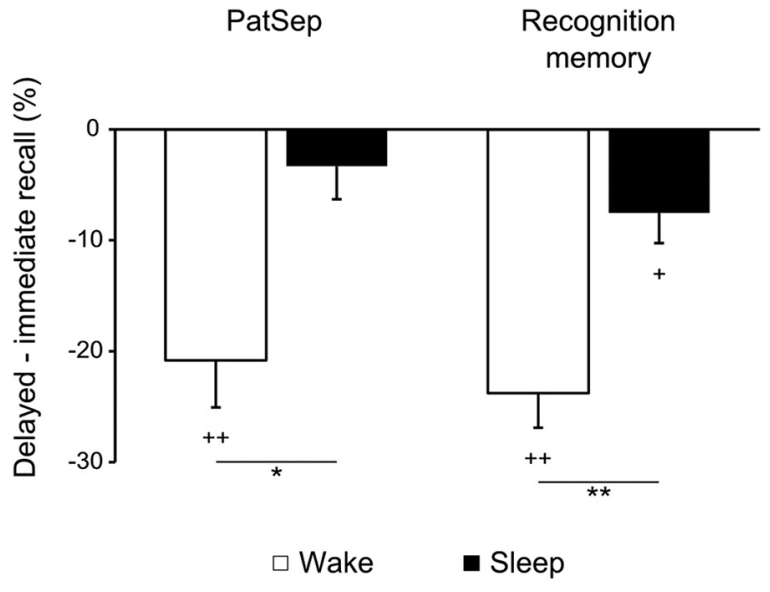

Figure 2. PatSep and recognition memory performance separately for the Sleep (black) and Wake (white) conditions. Mean ( \pm SEM) difference values (delayed minus immediate recall performance) are given. PatSep performance deteriorates across the wake interval but remains stable across sleep. ${ }^{*} p<0.05 ;{ }^{* *} p<0.01$, for pairwise comparisons between conditions. $+p<0.05 ;++p<0.01$, for test against zero.

reversed for the most similar lures (lure 1) showing higher PatSep scores after wakefulness than after sleep $\left(t_{(12)}=2.33, p=0.038\right)$.

The diminished PatSep score for highly similar lures compared with wakefulness lead to the assumption that participants were here more prone to incorrectly responding "old" to lures instead of "similar." To prove the hypothesis, we also calculated the $2 \times 5$ (Sleep/Wake $\times$ similarity) ANOVA for the probability of incorrectly responding "old" to lures [i.e., also corrected for the response bias, as follows: $p$ (false old response to lures) $-p$ (false old response to foils)]. As expected, the results mirrored the findings regarding the PatSep score. For the least similar lure 5, the old responses were more frequent after wakefulness than after sleep $\left(t_{(12)}=4.69, p=0.001\right)$. Conversely, for the most similar lure 1 , they were more frequent after sleep than after wakefulness $\left(t_{(12)}=-2.57, p=0.025\right)$.

To further analyze the dependency of sleep versus wake effects on lure similarity, we calculated correlations between lure similarity and the PatSep score, separately for the Sleep and Wake conditions for every participant. As expected, at immediate recall in both conditions the PatSep score was positively correlated with lure similarity (i.e., PatSep scores were the higher the less similar the lure was; Sleep: $r_{s}=0.747 \pm 0.07, z=3.22, p=0.001$, for test against 0 ; Wake: $\left.r_{s}=0.735 \pm 0.07, z=3.19, p=0.001\right)$. The same positive correlation was found after sleep $\left(r_{s}=0.733 \pm 0.06, z=\right.$ $3.18, p=0.001$ ) but failed to reach significance after wakefulness $\left(r_{s}=0.249 \pm 0.14, z=1.80, p=0.071\right)$. Comparing averaged correlations across participants at immediate and delayed recall revealed that these coefficients significantly differed only in the Wake condition $(z=-2.41, p=0.016)$, whereas there was no difference in the Sleep condition $(z=-0.31, p=0.755$; Fig. $3 b)$.

\section{Sleep recordings, slow oscillations, and spindles}

Participants in the Sleep condition displayed normal sleep (total sleep time, $446.2 \pm 7.1 \mathrm{~min}$; sleep onset latency, $29.0 \pm 5.1 \mathrm{~min}$; sleep time in stage 1, $49.8 \pm 6.9 \mathrm{~min}$; sleep time in stage 2, $196.2 \pm$ $10.9 \mathrm{~min}$; sleep time in SWS: $105.1 \pm 6.3 \mathrm{~min}$; sleep time in REM sleep, $64.3 \pm 8.0 \mathrm{~min}$; movement time, $10.3 \pm 5.9 \mathrm{~min}$ ). None of these parameters correlated with the PatSep score (all $p$ values $>0.28$ )

Correlations between specific EEG oscillatory measures and the PatSep score are summarized in Table 2. Robust relations 
Table 1. Overview of responses in the MST in Sleep and Wake conditions

\begin{tabular}{|c|c|c|c|c|c|c|c|c|c|}
\hline \multirow[b]{2}{*}{ Item type } & \multicolumn{3}{|l|}{ Target } & \multicolumn{3}{|l|}{ Lure } & \multicolumn{3}{|l|}{ Foil } \\
\hline & Old & Similar & New & Old & Similar & New & Old & Similar & New \\
\hline \multicolumn{10}{|l|}{ Sleep } \\
\hline Immediate recall & $83.54(3.16)$ & 13.54 (3.02) & $3.00(0.90)$ & $37.92(4.01)$ & $54.69(3.85)$ & $7.23(1.46)$ & $1.31(0.31)$ & $19.23(3.44)$ & $79.77(3.38)$ \\
\hline Delayed recall & $79.08(2.40)$ & 15.77 (1.82) & $5.23(1.00)$ & $32.69(3.14)$ & $50.69(3.18)$ & $16.62(2.52)$ & 4.38 (1.29) & $18.46(2.98)$ & $77.15(3.07)$ \\
\hline \multicolumn{10}{|l|}{ Wake } \\
\hline Immediate recall & $85.62(2.86)$ & $12.31(2.62)$ & $2.15(0.82)$ & $30.62(3.99)$ & $62.38(3.72)$ & $6.85(1.43)$ & $2.46(0.31)$ & $19.69(4.43)$ & $78.23(4.47)$ \\
\hline Delayed recall & $62.62(4.89)$ & $26.85(4.48)$ & $10.46(1.97)$ & $32.08(3.52)$ & 38.69 (3.25) & $29.54(2.69)$ & $3.23(0.84)$ & $16.77(2.77)$ & $80.08(2.93)$ \\
\hline
\end{tabular}

Mean (SEM) of response types relative to item types in percentage.
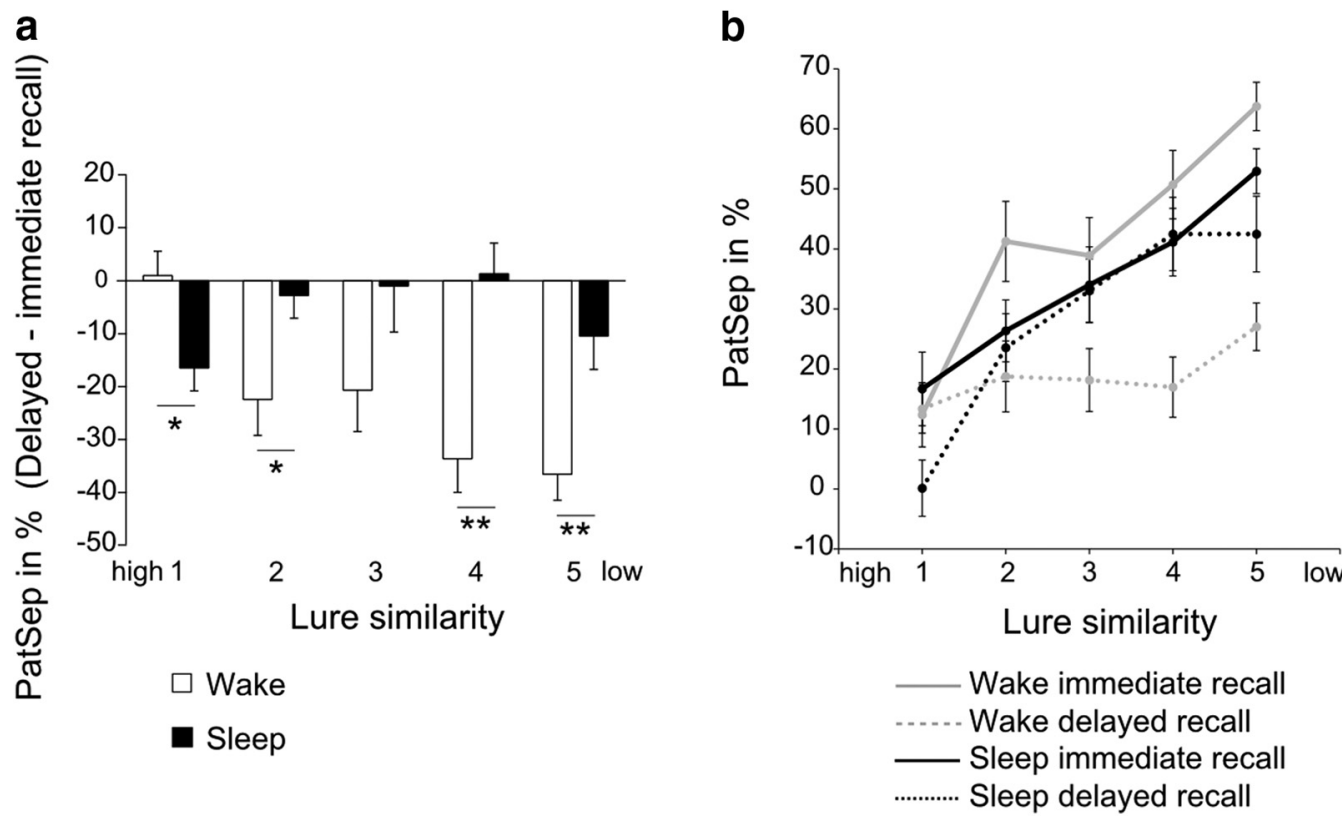

Figure 3. Pattern separation performance as a function of lure similarity. $\boldsymbol{a}$, Mean ( \pm SEM) PatSep score across five degrees of lure similarity (1, high similarity; 5 , low similarity) separately for the Sleep (black) and Wake (white) conditions. ${ }^{*} p<0.05 ;{ }^{* *} p<0.01$ for pairwise comparisons between Sleep and Wake conditions. Difference values (delayed minus immediate recall) are indicated. $\boldsymbol{b}$, Mean ( \pm SEM) PatSep scores separately at immediate and delayed recall for the Sleep and Wake conditions depict graded decrease and increase in performance. Note the typical increase in pattern separation performance with decreasing lure similarity seen before sleep and wakefulness intervals (immediate recall) is preserved after sleep but deteriorates after wakefulness (delayed recall).

were revealed for non-REM sleep spindles and slow oscillations. Spindle density as well as slow oscillation density during nonREM sleep were positively correlated with PatSep performance (for central electrode sites: spindles: $r=0.683, p=0.014$; slow oscillations: $r=0.613, p=0.026$; Fig. $4 a, b)$. Considering evidence that the occurrence of hippocampal memory reactivations is synchronized to neocortical slow oscillation and thalamic spindle activity (Sirota et al., 2003; Staresina et al., 2015), we also explored the relationship of EEG activity occurring phase-locked to the slow oscillation $( \pm 1.5 \mathrm{~s}$ around the negative slow oscillation peak) with PatSep performance. The analyses revealed a positive correlation between PatSep performance and phase-locked $(4-8 \mathrm{~Hz})$ theta power with a maximum at central channels (at C3: $r=0.589, p=0.044$; Fig. $4 c$ ). There was no correlation of PatSep performance with $(12-16 \mathrm{~Hz})$ spindle activity occurring phase-locked to the slow oscillation.

\section{Discussion}

Our study in humans shows that pattern separation performance stabilized after sleep but deteriorated across a period of wakefulness. The stabilizing effect of sleep on pattern separation was most pronounced for lures with lowest similarity to the target stimulus. For stimuli with the greatest similarity to targets, pattern separation performance after postencoding sleep was signif- icantly lower than after the wake period. Particularly, we found EEG spindle and slow oscillation density, as well as slow oscillationlocked theta activity during non-REM sleep to be positively correlated with overnight changes in pattern separation performance. The picture arising from these findings is consistent with the notion that neural replay during sleep strengthens hippocampal representations such that similarity-dependent computations of pattern separation are stabilized.

Revealing superior recognition performance after sleep compared with wakefulness, our findings confirm previous studies indicating that sleep supports the formation of distinct representations for discriminative stimuli (Gais et al., 2000; Stickgold et al., 2000; Drosopoulos et al., 2005; Ellenbogen et al., 2009; Fenn et al., 2009; Maurer et al., 2015). The present data go beyond these previous data by indicating that sleep changes recognition behavior strongly depending on the similarity of lures to target stimuli. The clear switch from similar to old responses regarding highly similar lures across sleep may suggest a predomination of pattern completion processes over pattern separation (Toner et al., 2009; Yassa et al., 2010). If this was the case, our results may indicate that reprocessing of representations during sleep simultaneously affects both modes of pattern separation and pattern completion. However, it should also be mentioned here that the validity of the 
Table 2. Power density, slow oscillations, and spindles: correlations with pattern separation performance

\begin{tabular}{lccc}
\hline & & \multicolumn{2}{c}{$\begin{array}{l}\text { Correlations with PatSep } \\
\text { retention score }\end{array}$} \\
\cline { 3 - 4 } & Mean (SEM) & $r$ & $p$ \\
\hline Power density $\left(\mu \mathrm{V}^{2} / \mathrm{Hz}\right)$ & & & \\
$0.5-1 \mathrm{~Hz}$ & $329.58(38.16)$ & 0.352 & 0.238 \\
$0.5-4 \mathrm{~Hz}$ & $112.27(11.80)$ & 0.234 & 0.441 \\
$1-4 \mathrm{~Hz}^{a}$ & $86.11(9.24)$ & 0.143 & 0.642 \\
$4-8 \mathrm{~Hz}^{a}$ & $7.55(0.77)$ & -0.236 & 0.437 \\
$9-12 \mathrm{~Hz}^{a}$ & $3.18(0.66)$ & -0.352 & 0.239 \\
$12-15 \mathrm{~Hz}^{a}$ & $3.53(0.43)$ & -0.104 & 0.734 \\
Slow oscillations & & & \\
Count & $1130.23(90.91)$ & 0.408 & 0.166 \\
Density $(/ 30 \mathrm{~s})$ & $1.93(0.11)$ & $0.613^{*}$ & 0.026 \\
Amplitude $(\mu \mathrm{V})^{a}$ & $169.02(6.84)$ & 0.197 & 0.519 \\
Slope $(\mu \mathrm{V} / \mathrm{s})$ & $401.16(17.72)$ & 0.215 & 0.480 \\
Spindles & & & \\
Count & $1659.91(67.68)$ & 0.039 & 0.909 \\
Density $(/ 30 \mathrm{~s})$ & $2.79(0.05)$ & $0.683^{*}$ & 0.014 \\
Length $(s)$ & $0.85(0.01)$ & -0.055 & 0.866 \\
Amplitude $(\mu \mathrm{V})$ & $31.22(1.46)$ & -0.456 & 0.159 \\
\hline
\end{tabular}

Data are the mean (SEM) for power within distinct EEG frequency bands, slow oscillation, and spindle parameters. Right columns indicate correlations with the PatSep retention score and respective $p$ values.

${ }^{a}$ Correlations for frequency bands that were not normally distributed were calculated with Spearman's $\rho$, all others with Pearson product-moment correlation.

${ }^{*} p<0.05$.

MST as a measure of hippocampal pattern separation and completion performance has been questioned (Liu et al., 2016). Specifically, the definition of pattern completion performance judging similar lures as old assuming a generalization process regarding targetlure pairs (Yassa and Stark, 2011) does not represent its theoretical construct as the reactivation of memory representations based on noisy or degraded input accurately (Hunsaker and Kesner, 2013). Consequently, since we could only show a shift toward pattern completion indirectly, our interpretation in this regard remains speculative. As the MST has already been validated in several studies for the assessment of pattern separation performance (Yassa et al., 2010, 2011a, Lacy et al., 2011), the paradigm is well suited for comparing our results with previous findings regarding pattern separation, so that we concentrated on those results. Indeed, the pattern separation performance assessed immediately after encoding in both the Sleep and Wake condition was comparable to those of corresponding age groups examined in previous studies (Toner et al., 2009; Yassa et al., 2011b; Stark et al., 2013). While the MST has been used mainly in conjunction with an immediate recall test, we here use this task for assessing how reprocessing affects memory representations across longer retention periods of sleep and wakefulness. Across wakefulness, pattern separation particularly deteriorated, which is reminiscent of changes seen in aged humans (Yassa et al., 2011b; Stark et al., 2013) and in patients with conditions including deficits in episodic memory such as Alzheimer's disease (Ally et al., 2013), mild cognitive impairment (Yassa et al., 2010), and hippocampal damage (Kirwan et al., 2012). Recently, sleep deprivation was identified as another factor interfering with successful pattern separation at memory encoding (i.e., in an immediate recall test) whereby the impairment was restored after a recovery nap (Saletin et al., 2016).

Importantly, in comparison with wakefulness, sleep did not uniformly improve pattern separation performance at all levels of lure similarity, but for lures with the highest similarity to the targets sleep diminished pattern separation. Evidence from studies of neural activity in rats indicates that the dentate gyrus and
CA3 are simultaneously engaged in the processing of pattern separation and completion such that at a certain degree of similarity to a previously learned stimulus, acute stimulus input favors pattern completion operations (Guzowski et al., 2004; Lee et al., 2004; Leutgeb et al., 2004; Vazdarjanova and Guzowski, 2004). Considering this switch from pattern separation to pattern completion with increasing target similarity as a hallmark of hippocampal information processing, the present observation that sleep enhanced pattern separation of dissimilar lures and diminished pattern separation of lures highly similar to the target corroborates the view of a direct impact of sleep on the hippocampal representation of the target stimuli. Neural assembly pattern reactivations during sleep might counter trace decay and, thus, keep the hippocampal representation shaped such that operations of pattern separation are enhanced to stimulus inputs of graded similarity, in comparison with the effects of postencoding wakefulness.

On the other side, the pattern of changes rules out a nonspecific effect of sleep generally enhancing discriminability of stimulus inputs. Other nonspecific confounding effects can likewise be excluded. There are hints that encoding and recall of declarative memory can be affected by circadian factors (Tilley and Warren, 1983). Indeed, in the Sleep and Wake conditions of the present experiments these processes took place at different circadian phases, to avoid stress-inducing effects of sleep deprivation impairing pattern separation (Saletin et al., 2016). However, morning and evening sessions in these conditions differed neither in immediate recall performance on the MST nor in vigilance and tiredness, rendering it unlikely that nonspecific changes in executive function substantially contributed to the differential recall pattern after sleep and wakefulness. Furthermore, participants achieved scores on immediate recall similar to those reported in previous studies (Stark et al., 2013), so that conditions are not only comparable to each other but also to findings beyond our experiment.

Also our exploratory analysis of relations to sleep EEG oscillatory parameters highlighted consistent positive correlations of spindle and slow-oscillation density as well as of theta activity occurring phase-locked to slow oscillations with pattern separation performance after sleep, which further corroborates the view of sleep, specifically non-REM sleep, being the primary factor mediating the effects on hippocampal memory. The correlation with sleep spindle density, a measure being independent of the duration of non-REM sleep, underscores the idea that spindles are genuinely involved in processes of memory consolidation. Indeed, a large body of findings suggests that spindle activity originating from thalamic networks enhances consolidation in different memory domains, including hippocampus-dependent spatial memories (Meier-Koll et al., 1999; Gais et al., 2002; Schabus et al., 2004; Eschenko et al., 2006; Saletin et al., 2011). Spindles phase lock hippocampal ripples and co-occurring neural memory reactivations to the excitable trough of the spindle oscillation (Clemens et al., 2007; Bergmann et al., 2012; Staresina et al., 2015). Concurrently, the slow oscillations drive hippocampal ripples and neural reactivations such that they preferentially occur during the depolarizing slow-oscillation up phase (Sirota et al., 2003; Ji and Wilson, 2007; Staresina et al., 2015).

Against this backdrop, improved pattern separation performance associated with enhanced spindle and slow oscillation density might reflect that memory reactivation and ripples occurring in hippocampal networks during the excitable phase of the spindle and slow oscillation cycle, respectively, are more effective in keeping the respective memory representation. Enhanced EEG theta activity occurring in synchrony with the up-to-down transition of 
a

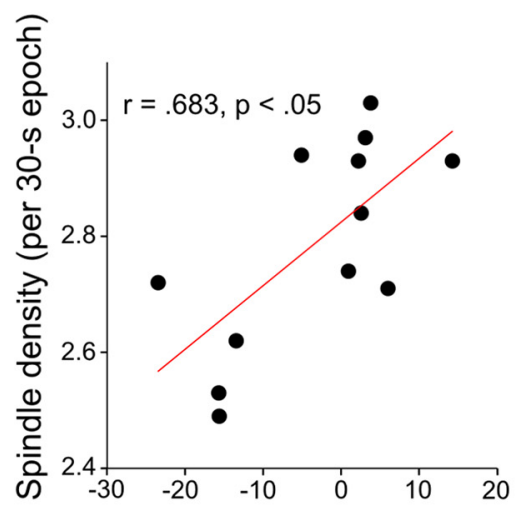

PatSep in \% (delayed - immediate recall) b

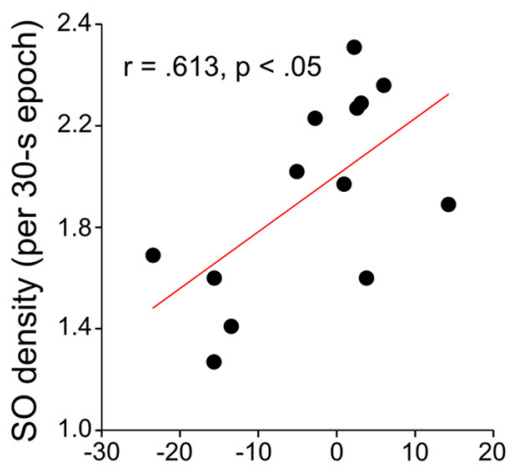

PatSep in \% (delayed - immediate recall)

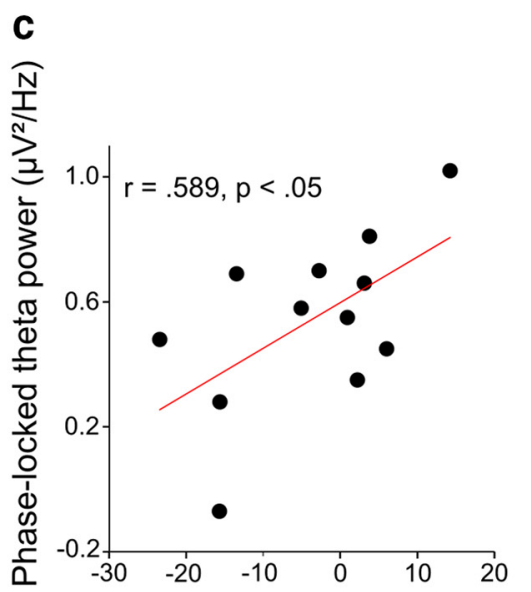

PatSep in \% (delayed - immediate recall)

d
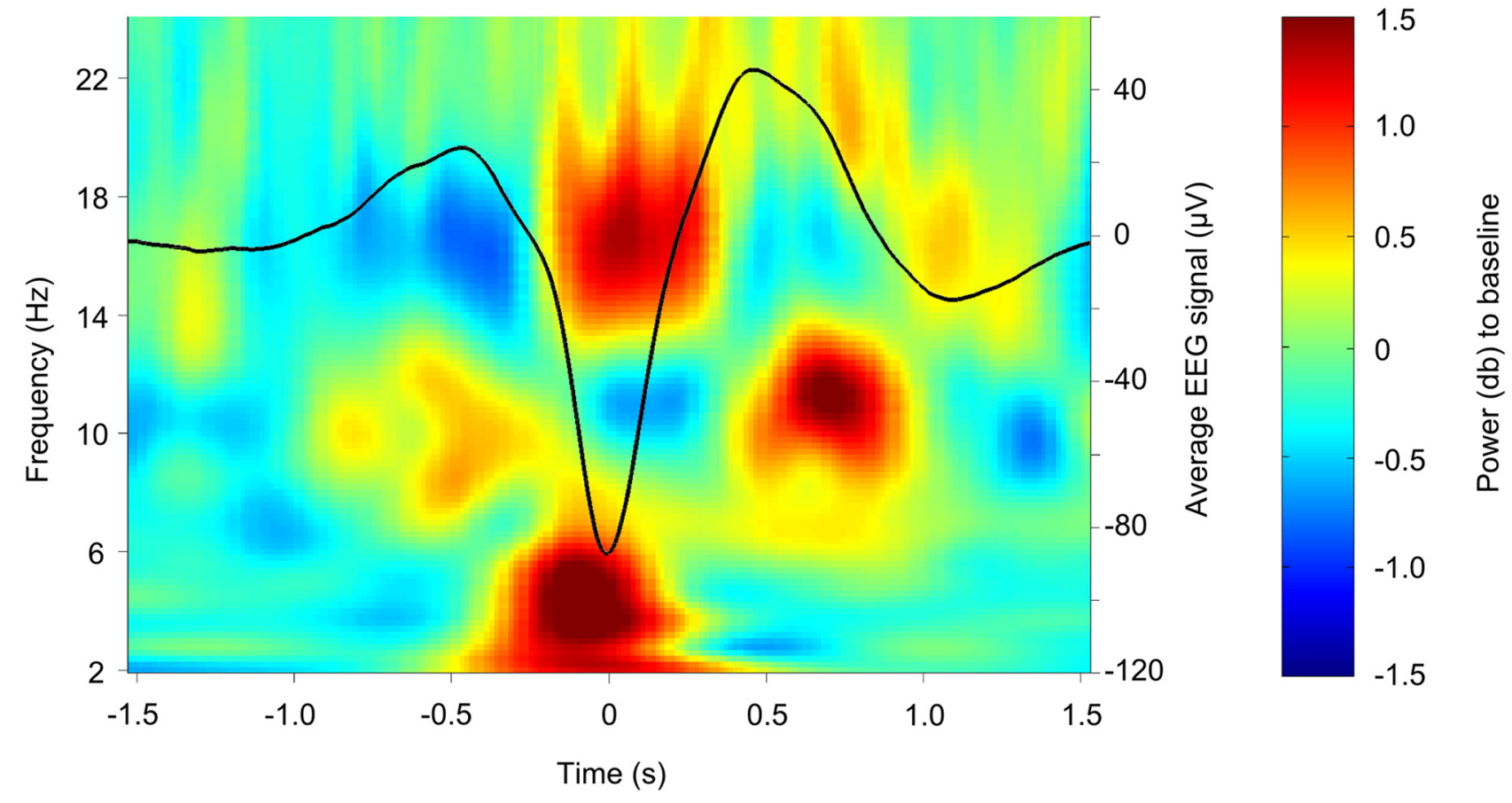

Figure 4. EEG spindle density, slow-oscillation density and slow oscillation-associated theta activity during non-REM sleep are related to pattern separation performance. $\boldsymbol{a}, \boldsymbol{b}$, Correlation between PatSep performance and spindle density $(\boldsymbol{a} ; n=12)$ and slow oscillation density $(\boldsymbol{b} ; n=13)$ during non-REM sleep (SWS and S2, recordings from C3/C4). $\boldsymbol{c}$, Correlation between PatSep performance and phase-locked theta $(4-8 \mathrm{~Hz}$ ) power (at (3) during slow oscillation (i.e., in a -0.5 to $0.25 \mathrm{~s}$ window around the negative slow oscillation peak; $n=12$ ). Slow 0 scillations were identified in non-REM sleep (SWS and S2). $\boldsymbol{d}$, Averaged time-frequency plot of EEG wavelet power during slow oscillations (at (3) in a \pm 1.5 s time window around the negative slow oscillation peak $(0 \mathrm{~s})$ for a $2-24 \mathrm{~Hz}$ frequency band ( $n=12)$.

the slow oscillation might likewise be connected to a more effective hippocampal processing of memory information. In the wake state, theta oscillations are robust indicators of ongoing encoding and retrieval in hippocampal networks (Klimesch et al., 2006; Nyhus and Curran, 2010). Similarly, during sleep, increases in frontal EEG theta activity were observed in humans when hippocampal memory representations were experimentally reactivated by presenting reminder cues during non-REM sleep (Schreiner and Rasch, 2015; Schreiner et al., 2015). The cuing-evoked increase in theta activity might well reflect re-encoding of information during hippocampal reactivation, although the origin of scalp-recorded EEG theta activity in humans is obscure (Klimesch, 1996; Klimesch et al., 1996). In natural conditions, the neocortical slow oscillation synchronizes neural reactivations of memory information in hippocampal networks to the slow oscillation upstate (Ji and Wilson, 2007; Diekelmann and Born, 2010). Against this backdrop, our observation of a positive correlation between pattern separation performance after sleep and theta activity occurring in synchrony with the slow oscillation during sleep fits well with the notion that hippocampal memory reactivations go along with a re-encoding and shaping of the hippocampal representations, thereby enhancing pattern separation and completion during the processing of stimuli with graded similarity. Altogether, our findings provide first-time evidence in humans supporting the notion that reactivation-based consolidation processes during sleep affect the hippocampal representation itself 
such that hippocampal computations of pattern separation are enhanced.

\section{References}

Ally BA, Hussey EP, Ko PC, Molitor RJ (2013) Pattern separation and pattern completion in Alzheimer's disease: evidence of rapid forgetting in amnestic mild cognitive impairment. Hippocampus 23:1246-1258. CrossRef Medline

Aschenbrenner S, Tucha O, Lange KW (2000) Regensburger Wortflüssigkeitstest. Göttingen, Germany: Testzentrale.

Bakker A, Kirwan CB, Miller M, Stark CE (2008) Pattern separation in the human hippocampal CA3 and dentate gyrus. Science 319:1640-1642. CrossRef Medline

Bartsch T, Schönfeld R, Müller FJ, Alfke K, Leplow B, Aldenhoff J, Deuschl G, Koch JM (2010) Focal lesions of human hippocampal CA1 neurons in transient global amnesia impair place memory. Science 328:1412-1415. CrossRef Medline

Bartsch T, Döhring J, Rohr A, Jansen O, Deuschl G (2011) CA1 neurons in the human hippocampus are critical for autobiographical memory, mental time travel, and autonoetic consciousness. Proc Natl Acad Sci U S A 108:17562-17567. CrossRef Medline

Bendor D, Wilson MA (2012) Biasing the content of hippocampal replay during sleep. Nat Neurosci 15:1439-1444. CrossRef Medline

Bennett IJ, Stark CE (2016) Mnemonic discrimination relates to perforant path integrity: an ultra-high resolution diffusion tensor imaging study. Neurobiol Learn Mem 129:107-112. CrossRef Medline

Bergmann TO, Mölle M, Diedrichs J, Born J, Siebner HR (2012) Sleep spindlerelated reactivation of category-specific cortical regions after learning facescene associations. Neuroimage 59:2733-2742. CrossRef Medline

Berron D, Schütze H, Maass A, Cardenas-Blanco A, Kuijf HJ, Kumaran D, DüzelE (2016) Strong evidence for pattern separation in human dentate gyrus. J Neurosci 36:7569-7579. CrossRef Medline

Buysse DJ, Reynolds CF 3rd, Monk TH, Berman SR, Kupfer DJ (1989) The Pittsburgh Sleep Quality Index: a new instrument for psychiatric practice and research. Psychiatry Res 28:193-213. CrossRef Medline

Clemens Z, Mölle M, Eross L, Barsi P, Halász P, Born J (2007) Temporal coupling of parahippocampal ripples, sleep spindles and slow oscillations in humans. Brain 130:2868-2878. CrossRef Medline

De Gennaro L, Ferrara M (2003) Sleep spindles: an overview. Sleep Med Rev 7:423-440. CrossRef Medline

Diekelmann S, Born J (2010) The memory function of sleep. Nat Rev Neurosci 11:114-126. CrossRef Medline

Drosopoulos S, Wagner U, Born J (2005) Sleep enhances explicit recollection in recognition memory. Learn Mem 12:44-51. CrossRef Medline

Ego-Stengel V, Wilson MA (2010) Disruption of ripple-associated hippocampal activity during rest impairs spatial learning in the rat. Hippocampus 20:1-10. CrossRef Medline

Ellenbogen JM, Hulbert JC, Jiang Y, Stickgold R (2009) The sleeping brain's influence on verbal memory: boosting resistance to interference. PLoS One 4:e4117. CrossRef Medline

Eschenko O, Mölle M, Born J, Sara SJ (2006) Elevated sleep spindle density after learning or after retrieval in rats. J Neurosci 26:12914-12920. CrossRef Medline

Fenn KM, Gallo DA, Margoliash D, Roediger HL 3rd, Nusbaum HC (2009) Reduced false memory after sleep. Learn Mem 16:509-513. CrossRef Medline

Gais S, Plihal W, Wagner U, Born J (2000) Early sleep triggers memory for early visual discrimination skills. Nat Neurosci 3:1335-1339. CrossRef Medline

Gais S, Mölle M, Helms K, Born J (2002) Learning-dependent increase in sleep spindle density. J Neurosci 22:6830-6834. Medline

Girardeau G, Benchenane K, Wiener SI, Buzsáki G, Zugaro MB (2009) Selective suppression of hippocampal ripples impairs spatial memory. Nat Neurosci 12:1222-1223. CrossRef Medline

Guzowski JF, Knierim JJ, Moser EI (2004) Ensemble dynamics of hippocampal regions CA3 and CA1. Neuron 44:581-584. CrossRef Medline

Hunsaker MR, Kesner RP (2013) The operation of pattern separation and pattern completion processes associated with different attributes or domains of memory. Neurosci Biobehav Rev 37:36-58. CrossRef Medline

Inostroza M, Born J (2013) Sleep for preserving and transforming episodic memory. Annu Rev Neurosci 36:79-102. CrossRef Medline
Ji D, Wilson MA (2007) Coordinated memory replay in the visual cortex and hippocampus during sleep. Nat Neurosci 10:100-107. CrossRef Medline

Karpicke JD, Roediger HL 3rd (2008) The critical importance of retrieval for learning. Science 319:966-968. CrossRef Medline

Kirwan CB, Hartshorn A, Stark SM, Goodrich-Hunsaker NJ, Hopkins RO, Stark CE (2012) Pattern separation deficits following damage to the hippocampus. Neuropsychologia 50:2408-2414. CrossRef Medline

Kirwan CB, Stark CE (2007) Overcoming interference: an fMRI investigation of pattern separation in the medial temporal lobe. Learn Mem 14: 625-633. CrossRef Medline

Klimesch W (1996) Memory processes, brain oscillations and EEG synchronization. Int J Psychophysiol 24:61-100. CrossRef Medline

Klimesch W, Doppelmayr M, Russegger H, Pachinger T (1996) Theta band power in the human scalp EEG and the encoding of new information. Neuroreport 7:1235-1240. CrossRef Medline

Klimesch W, Hanslmayr S, Sauseng P, Gruber W, Brozinsky CJ, Kroll NE, Yonelinas AP, Doppelmayr M (2006) Oscillatory EEG correlates of episodic trace decay. Cereb Cortex 16:280-290. CrossRef Medline

Lacy JW, Yassa MA, Stark SM, Muftuler LT, Stark CE (2011) Distinct pattern separation related transfer functions in human CA3/dentate and CA1 revealed using high-resolution $\mathrm{fMRI}$ and variable mnemonic similarity. Learn Mem 18:15-18. CrossRef Medline

Lee I, Yoganarasimha D, Rao G, Knierim JJ (2004) Comparison of population coherence of place cells in hippocampal subfields CA1 and CA3. Nature 430:456-459. CrossRef Medline

Lehrl S (2005) Mehrfach-Wortschatz-Intelligenztest: MWT-B. Balingen: Spitta Verlag.

Leutgeb JK, Leutgeb S, Moser MB, Moser EI (2007) Pattern separation in the dentate gyrus and CA3 of the hippocampus. Science 315:961-966. CrossRef Medline

Leutgeb S, Leutgeb JK, Treves A, Moser MB, Moser EI (2004) Distinct ensemble codes in hippocampal areas CA3 and CA1. Science 305:12951298. CrossRef Medline

Liu KY, Gould RL, Coulson MC, Ward EV, Howard RJ (2016) Tests of pattern separation and completion in humans-A systematic review. Hippocampus 26:705-717. CrossRef Medline

Maurer L, Zitting KM, Elliott K, Czeisler CA, Ronda JM, Duffy JF (2015) A new face of sleep: the impact of post-learning sleep on recognition memory for face-name associations. Neurobiol Learn Mem 126:31-38. CrossRef Medline

McClelland JL, McNaughton BL, O’Reilly RC (1995) Why there are complementary learning systems in the hippocampus and neocortex: insights from the successes and failures of connectionist models of learning and memory. Psychol Rev 102:419-457. CrossRef Medline

McNaughton BL, Morris RG (1987) Hippocampal synaptic enhancement and information storage within a distributed memory system. Trends Neurosci 10:408-415. CrossRef

Meier-Koll A, Bussmann B, Schmidt C, Neuschwander D (1999) Walking through a maze alters the architecture of sleep. Percept Mot Skills 88: 1141-1159. CrossRef Medline

Mölle M, Marshall L, Gais S, Born J (2002) Grouping of spindle activity during slow oscillations in human non-rapid eye movement sleep. J Neurosci 22:10941-10947. Medline

Mölle M, Bergmann TO, Marshall L, Born J (2011) Fast and slow spindles during the sleep slow oscillation: disparate coalescence and engagement in memory processing. Sleep 34:1411-1421. CrossRef Medline

Nelson HE (1982) The National Adult Reading Test (NART): Test Manual. Windsor, UK: NFER-Nelson.

Neunuebel JP, Knierim JJ (2014) CA3 retrieves coherent representations from degraded input: direct evidence for CA3 pattern completion and dentate gyrus pattern separation. Neuron 81:416-427. CrossRef Medline

Ngo HV, Martinetz T, Born J, Mölle M (2013) Auditory closed-loop stimulation of the sleep slow oscillation enhances memory. Neuron 78:545553. CrossRef Medline

Norman KA, O’Reilly RC (2003) Modeling hippocampal and neocortical contributions to recognition memory: a complementary-learning-systems approach. Psychol Rev 110:611-646. CrossRef Medline

Nyhus E, Curran T (2010) Functional role of gamma and theta oscillations in episodic memory. Neurosci Biobehav Rev 34:1023-1035. CrossRef Medline

Oldfield RC (1971) The assessment and analysis of handedness: the Edinburgh inventory. Neuropsychologia 9:97-113. CrossRef Medline 
O’Neill J, Pleydell-Bouverie B, Dupret D, Csicsvari J (2010) Play it again: reactivation of waking experience and memory. Trends Neurosci 33:220 229. CrossRef Medline

Oostenveld R, Fries P, Maris E, Schoffelen JM (2011) FieldTrip: open source software for advanced analysis of MEG, EEG, and invasive electrophysiological data. Comput Intell Neurosci 2011:156869. CrossRef Medline

O'Reilly RC, McClelland JL (1994) Hippocampal conjunctive encoding, storage, and recall: avoiding a trade-off. Hippocampus 4:661-682. CrossRef Medline

Rasch B, Born J (2013) About sleep's role in memory. Physiol Rev 93:681766. CrossRef Medline

Rasch B, Büchel C, Gais S, Born J (2007) Odor cues during slow-wave sleep prompt declarative memory consolidation. Science 315:1426-1429. CrossRef Medline

Reitan RM (1979) Trail making test (TMT). Göttingen, Germany: Hogrefe.

Rey A (1941) L'examen psychologique dans les cas d'encéphalopathie traumatique. Arch Psychol (Geneve) 28:21.

Riedner BA, Vyazovskiy VV, Huber R, Massimini M, Esser S, Murphy M, Tononi G (2007) Sleep homeostasis and cortical synchronization: III. A high-density EEG study of sleep slow waves in humans. Sleep 30:16431657. CrossRef Medline

Saletin JM, Goldstein AN, Walker MP (2011) The role of sleep in directed forgetting and remembering of human memories. Cereb Cortex 21:25342541. CrossRef Medline

Saletin JM, Goldstein-Piekarski AN, Greer SM, Stark S, Stark CE, Walker MP (2016) Human hippocampal structure: a novel biomarker predicting mnemonic vulnerability to, and recovery from, sleep deprivation. J Neurosci 36:2355-2363. CrossRef Medline

Schabus M, Gruber G, Parapatics S, Sauter C, Klösch G, Anderer P, Klimesch W, Saletu B, Zeitlhofer J (2004) Sleep spindles and their significance for declarative memory consolidation. Sleep 27:1479-1485. CrossRef Medline

Schreiner T, Rasch B (2015) Boosting vocabulary learning by verbal cueing during sleep. Cereb Cortex 25:4169-4179. CrossRef Medline

Schreiner T, Lehmann M, Rasch B (2015) Auditory feedback blocks memory benefits of cueing during sleep. Nat Commun 6:8729. CrossRef Medline

Sirota A, Csicsvari J, Buhl D, Buzsáki G (2003) Communication between neocortex and hippocampus during sleep in rodents. Proc Natl Acad Sci U S A 100:2065-2069. CrossRef Medline

Staresina BP, Bergmann TO, Bonnefond M, van der Meij R, Jensen O, Deuker L, Elger CE, Axmacher N, Fell J (2015) Hierarchical nesting of slow oscillations, spindles and ripples in the human hippocampus during sleep. Nat Neurosci 18:1679-1686. CrossRef Medline

Stark SM, Yassa MA, Lacy JW, Stark CE (2013) A task to assess behavioral pattern separation (BPS) in humans: data from healthy aging and mild cognitive impairment. Neuropsychologia 51:2442-2449. CrossRef Medline

Stickgold R, James L, Hobson JA (2000) Visual discrimination learning requires sleep after training. Nat Neurosci 3:1237-1238. CrossRef Medline

Tilley A, Warren P (1983) Retrieval from semantic memory at different times of day. J Exp Psychol Learn Mem Cogn 9:718-724. CrossRef Medline

Toner CK, Pirogovsky E, Kirwan CB, Gilbert PE (2009) Visual object pattern separation deficits in nondemented older adults. Learn Mem 16: 338-342. CrossRef Medline

Vazdarjanova A, Guzowski JF (2004) Differences in hippocampal neuronal population responses to modifications of an environmental context: evidence for distinct, yet complementary, functions of CA3 and CA1 ensembles. J Neurosci 24:6489-6496. CrossRef Medline

Wechsler D (1997) WMS-III Administration and scoring manual. San Antonio, TX: The Psychological Corporation.

Wilson MA, McNaughton BL (1994) Reactivation of hippocampal ensemble memories during sleep. Science 265:676-679. CrossRef Medline

Yassa MA, Stark SM, Bakker A, Albert MS, Gallagher M, Stark CE (2010) High-resolution structural and functional MRI of hippocampal CA3 and dentate gyrus in patients with amnestic mild cognitive impairment. Neuroimage 51:1242-1252. CrossRef Medline

Yassa MA, Mattfeld AT, Stark SM, Stark CE (2011a) Age-related memory deficits linked to circuit-specific disruptions in the hippocampus. Proc Natl Acad Sci U S A 108:8873-8878. CrossRef Medline

Yassa MA, Lacy JW, Stark SM, Albert MS, Gallagher M, Stark CE (2011b) Pattern separation deficits associated with increased hippocampal CA3 and dentate gyrus activity in nondemented older adults. Hippocampus 21:968-979. CrossRef Medline

Yassa MA, Stark CE (2011) Pattern separation in the hippocampus. Trends Neurosci 34:515-525. Medline 